\title{
ENRAIZAMENTO DE ESTACAS LENHOSAS E HERBÁCEAS DE CULTIVARES DE CAQUIZEIRO COM DIFERENTES CONCENTRAÇÕES DE ÁCIDO INDOLBUTÍRICO ${ }^{1}$
}

\author{
DÉBORA COSTA BASTOS ${ }^{2}$, RAFAEL PIO ${ }^{3}$, JOÃO ALEXIO SCARPARE FILHO ${ }^{4}$, MARILIA NEUBERN LIBARDI ${ }^{5}$, \\ LUIS FELIPE PAES DE ALMEIDA ${ }^{5}$, FÁBIO ALBUQUERQUE ENTELMANN ${ }^{5}$
}

\begin{abstract}
RESUMO - Desenvolveu-se este trabalho com o objetivo de estudar a capacidade de enraizamento de estacas lenhosas e herbáceas de cultivares de caquizeiro tratadas com AIB. Estacas lenhosas e herbáceas foram coletadas de ramos de caquizeiro das cultivares Pomelo, Rama Forte, Taubaté, Giombo e Fuyu e submetidas à aplicação de AIB $\left(0 ; 3.000\right.$ e $6.000 \mathrm{mg} . \mathrm{L}^{-1}$ por vinte segundos). Em seguida, as estacas foram colocadas em canteiro contendo uma mistura de terra + esterco de curral (3:1 v/v) como substrato (estacas lenhosas) e em bandejas de poliestireno expandido, contendo vermiculita média, em câmara de nebulização intermitente (estacas herbáceas). Como conclusão, observou-se que as cultivares de caquizeiro apresentam diferenças quanto ao potencial de formação de raízes e brotações; estacas herbáceas apresentam maior tendência na propagação via estaquia em comparação às estacas lenhosas.
\end{abstract}

Termos para indexação: Diospyrus kaki L., estaquia, AIB.

\section{ROOTING OF HARDWOOD AND HERBACEOUS CUTTINGS OF JAPANESE PERSIMMON TREE CULTIVARS TREATED WITH DIFFERENT CONCENTRATION OF INDOLBUTYRIC ACID}

\begin{abstract}
This work was carried out with the objective to study the capacity of rooting of hardwood and herbaceous cuttings of Japanese persimmon tree cultivars treated with IBA. Hardwood and herbaceous cuttings were collected from branches of Japanese persimmon tree and submitted to treatments in function of cultivars (Pomelo, Rama Forte, Taubaté, Giombo and Fuyu) and of application of IBA (0, 3,000 and 6,000 mg.L${ }^{1}$ for twenty seconds). Later the cuttings were placed in stonemason containing a soil mixture + corral manure (3:1 v/v) as substrate (hardwood cuttings) and in polyethylene trays containing vermiculite as substrate, in intermittent mist chamber (herbaceous cuttings). As conclusion is observed that the cultivars of Japanese persimmon tree present differences in relationship to potential of roots and shoots formation; herbaceous cuttings present higher tendency in the propagation through cutting in comparison with the hardwood cuttings.
\end{abstract}

Index terms: Diospyrus kaki L., cutting, IBA.

O caqui (Diospyrus kaki L.), pertencente à família Ebenaceae, é uma planta tipicamente de clima subtropical. É uma frutífera originária da Ásia, tendo o Japão como maior produtor mundial, sendo que, recentemente, seu cultivo vem crescendo significativamente em países como Israel, Estados Unidos, Itália, Brasil e Nova Zelândia (Tao \& Sugiura, 1992).

Sua propagação comercial é realizada pela enxertia por garfagem ou borbulhia, utilizando-se de porta-enxertos provenientes de sementes. Neste caso, podem ser utilizados os caquis comuns ( $D$. kaki L.), que apresentam sistema radicular pivotante e poucas raízes secundárias ou os caquis americanos (D. virginiana), que possuem sistema radicular fasciculado. No Brasil, devido à inexistência de programas de produção de mudas que envolvam a utilização dos caquis americanos ou ainda a existência de um caqui com potencial de utilização como porta-enxerto, a única alternativa é a extração de sementes das próprias cultivares comerciais para a formação dos porta-enxertos, que apresentam o inconveniente de nem todas possuírem sementes e, quando possuem, são escassas (Pio et al., 2003), além do baixo poder germinativo das sementes. Além disso, há uma grande variabilidade genética dos porta-enxertos devido à segregação envolvida no processo de multiplicação via semente (Pasqual et al., 2001; Hartmann et al., 2002).

Uma alternativa para o caquizeiro seria a formação de mudas pelo método da estaquia, com a utilização de estacas lenhosas coletadas na época da poda hibernal, realizada nos meses de julho a agosto ou ainda a utilização de estacas herbáceas coletadas junto à desbrota, 60 dias após a quebra da dormência (Pio et al., 2003). Esse método seria interessante por proporcionar redução no tempo de formação das mudas e dar origem a pomares mais homogêneos, representando uma evolução no seu cultivo.

A propagação de várias espécies frutíferas, pela estaquia, tem sido sugerida por vários autores, porém os resultados são variáveis de acordo com um grande número de fatores internos e externos. Destacamse, como fatores internos, a condição fisiológica da planta-matriz, a idade da planta, o tipo de estaca, a época do ano para coleta, o potencial genético do enraizamento, a sanidade do material e o balanço hormonal (Fachinello et al., 1995). Tem-se observado que o enraizamento de estacas de espécies de difícil enraizamento pode ser conseguido se forem fornecidos fatores adequados para o enraizamento das mesmas. A busca de técnicas auxiliares, como o uso de reguladores de crescimento, tem sido utilizada com freqüência a fim de proporcionar melhoria do enraizamento (Biasi, 1996). O uso de reguladores de crescimento tem por finalidade aumentar a porcentagem de estacas enraizadas, acelerar a iniciação radicular, aumentar o número e a qualidade das raízes formadas e uniformizar o enraizamento (Fachinello et al., 1995). O grupo de reguladores de crescimento usado com maior frequiência é o das auxinas (Hinojosa, 2000). De acordo com Hartmann et al. (2002), as auxinas são as substâncias mais importantes, que desempenham maiores funções no enraizamento de estacas. Entre as principais funções biológicas das auxinas, pode-se citar o crescimento de órgãos, especialmente as raízes. A auxina de presença natural é sintetizada principalmente em gemas apicais e em folhas jovens e, de maneira geral, move-se através da planta, do ápice para a base. Uma das formas mais comuns de favorecer o balanço hormonal para o enraizamento é a aplicação exógena de reguladores de crescimento, tais como o ácido indolbutírico (AIB) (Pasqual et al., 2001).

Devido à escassez de estudos e resultados relevantes à propagação por estaquia do caquizeiro, desenvolveu-se este trabalho com o objetivo de estudar o enraizamento de estacas lenhosas e herbáceas de cinco cultivares de caquizeiro mediante tratamento com diferentes concentrações de AIB.

\footnotetext{
${ }^{1}$ (Trabalho 143/2004). Recebido: 08/10/2004. Aceito para publicação: 06/04/2005.

${ }^{2}$ Eng $^{\circ}$. Agrônoma, M.Sc., Doutoranda em Fitotecnia, Depto. de Produção Vegetal, ESALQ/USP. Av. Pádua Dias, 11 - CP. 09, 13418-900, Piracicaba-SP. Autora correspondente: dcbastos@esalq.usp.br

${ }^{3}$ Eng $^{\circ}$. Agrônomo, M.Sc., PqC. Centro APTA Frutas, Instituto Agronômico de Campinas - IAC. Av. Luiz Pereira dos Santos, 1500 - Corrupira, 13214-820, JundiaíSP. Doutorando em Fitotecnia, Depto. de Produção Vegetal, ESALQ/USP. rafaelpio@iac.sp.gov.br

${ }^{4}$ Eng $^{\text {}}$. Agrônomo, Professor Doutor Associado do Depto. de Produção Vegetal, ESALQ/USP, Piracicaba-SP. jascarpa@esalq.usp.br

${ }^{5}$ Graduanda (o) em Engenharia Agronômica, ESALQ/USP, Piracicaba-SP.
} 
Para a realização deste estudo, dois experimentos foram conduzidos na área de produção de mudas do Departamento de Produção Vegetal da ESALQ/USP.

Para o primeiro ensaio, foram coletadas estacas lenhosas da porção mediana de ramos de caquizeiro na época da poda da cultura (agosto), padronizadas com $20 \mathrm{~cm}$ de comprimento, $0,8 \mathrm{~cm}$ de diâmetro e dotadas de 5-6 gemas. No segundo ensaio, coletaram-se estacas herbáceas da porção mediana de ramos no mês de outubro, padronizadas com $15 \mathrm{~cm}$ de comprimento, $0,6 \mathrm{~cm}$ de diâmetro e dotadas de 4-5 gemas, sendo mantido um par de folhas na extremidade apical. As cultivares utilizadas para ambos os ensaios foram: Pomelo, Rama Forte, Taubaté, Giombo e Fuyu. As estacas foram tratadas com AIB nas concentrações: 0; 3.000 e $6.000 \mathrm{mg} . \mathrm{L}^{-1}$ por vinte segundos, imergindo-se dois centímetros da extremidade basal. As estacas lenhosas foram colocadas em canteiro $(5 \mathrm{x} 1 \mathrm{~m})$ contendo uma mistura de terra + esterco de curral $(3: 1 \mathrm{v} / \mathrm{v})$ como substrato, enterradas até a metade de seu comprimento, cobertas com sombrite $50 \%$ e submetidas a irrigações manuais diárias, e as estacas herbáceas foram colocadas em bandejas de poliestireno expandido, contendo vermiculita média como substrato e colocadas para enraizar em câmara de nebulização intermitente (temperatura de $25 \pm 5^{\circ} \mathrm{C}$, UR média de $72 \%$, tempo de aspersão de 20 segundos, em intervalos de 10 minutos).

O delineamento utilizado para cada ensaio foi o inteiramente casualizado, em esquema fatorial $5 \times 3$, constituído pelas cinco cultivares e pelas três concentrações de AIB, com três repetições e doze estacas por unidade experimental. No primeiro ensaio, foram avaliadas as porcentagens de sobrevivência, estacas brotadas, enraizadas e calejadas no final de 90 dias. No segundo ensaio, após 120 dias, foram avaliadas as porcentagens de estacas enraizadas, a sobrevivência, a formação de calos, a brotação e o número de raízes por estaca.

Os dados foram submetidos à análise de variância e as médias, ao teste Scott-Knott (1974), ao nível de 5\% de probabilidade (Gomes, 2000). As análises foram realizadas pelo programa computacional Sistema para Análise de Variância - SISVAR (Ferreira, 2000), sendo os dados transformados em arc-sen $\sqrt{x \quad 0,5}$.

Através da análise de variância, constatou-se que, para o ensaio envolvendo as estacas lenhosas de caquizeiro, não houve formação de raízes e calos nas estacas em nenhuma das cultivares estudadas. Porém, houve formação de brotações nas estacas e sobrevivência, havendo apenas diferença estatística e interação entre as cultivares e as concentrações de AIB para a porcentagem de sobrevivência. Entretanto, no caso das estacas herbáceas, não houve efeito da utilização de AIB para nenhuma das variáveis analisadas, apenas diferença estatística para a porcentagem de sobrevivência, formação de calos e número de raízes por estaca entre as cultivares.

No final do ensaio, verificou-se que poucas brotações permaneceram nas estacas lenhosas, mas a maioria das estacas ainda permaneceu viva. As cultivares Pomelo e Giombo apresentaram maior sobrevivência de suas estacas, porém, para a cultivar Pomelo, a maior sobrevivência foi adquirida na ausência de tratamento com auxina, ao contrário da cultivar Giombo, que apresentou maior sobrevivência de suas estacas quando estas foram tratadas com $3.000 \mathrm{mg} . \mathrm{L}^{-1}$ de AIB (Tabela
TABELA 1 - Porcentagem de sobrevivência (PS) de estacas lenhosas de cultivares de caquizeiro aos 90 dias após o estaqueamento. ESALQ/USP, Piracicaba-SP, 2004.

\begin{tabular}{|c|c|c|c|}
\hline \multirow{3}{*}{ Cultivares } & \multicolumn{3}{|c|}{ PS (\%)* } \\
\hline & \multicolumn{3}{|c|}{ AIB (mg.L $\left.{ }^{-1}\right)$} \\
\hline & 0 & 3000 & 6000 \\
\hline Pomelo & $75,13 \quad \mathrm{Aa}$ & $47,30 \mathrm{Bb}$ & $47,21 \quad \mathrm{Ba}$ \\
\hline Rama Forte & $47,21 \quad \mathrm{Ab}$ & $43,36 \mathrm{Ab}$ & $24,25 \mathrm{Bbc}$ \\
\hline Taubaté & $23,50 \mathrm{Ac}$ & $29,12 \quad \mathrm{Abc}$ & 19,29 Ac \\
\hline Giombo & $55,08 \mathrm{Bab}$ & $83,73 \mathrm{Aa}$ & $45,29 \mathrm{Bab}$ \\
\hline Fuyu & 43,29 Abc & $9,00 \quad \mathrm{Bc}$ & $11,67 \mathrm{Bc}$ \\
\hline CV (\%) & \multicolumn{3}{|c|}{23,35} \\
\hline
\end{tabular}

* Médias seguidas pela mesma letra, maiúscula na linha e minúscula na coluna, não diferem entre si, pelo teste Scott-Knott, ao nível de 5\% de probabilidade.

1). Já para as demais cultivares, nota-se também que não houve maior porcentagem de sobrevivência na presença da mesma concentração de AIB, sendo que, para as cultivares Rama Forte e Fuyu, a maior sobrevivência das estacas foi constatada na ausência de tratamento e, para a cultivar Taubaté, com o tratamento de $3.000 \mathrm{mg}$. $\mathrm{L}^{-1}$ de AIB.

Apesar de não ter ocorrido enraizamento e formação de calos nas estacas lenhosas, pressupõe que a quantidade de auxina endógena nas estacas é baixa, uma vez que, em algumas cultivares, a presença de AIB aumentou a taxa de sobrevivência, a exemplo da cultivar Giombo, que teve aumento de $28,65 \%$ de sobrevivência de suas estacas quando essas foram tratadas com 3.000 mg.L. ${ }^{-1}$ de AIB, mas diminuição de 38,44\% quando essas foram tratadas com $6.000 \mathrm{mg} . \mathrm{L}^{-1}$ (Tabela 1). As auxinas são diretamente relacionadas com a formação de raízes nas estacas, mas sua presença estimula demais reações, como a divisão celular, além de apresentarem relações bastante importantes com ácidos nucléicos e proteínas, modificações da parede celular e estimulação de atividades enzimáticas e o crescimento de órgãos (Alvarenga, 1990; Figueiredo et al., 1995).

Já para as estacas herbáceas, a cultivar Taubaté apresentou maior porcentagem de sobrevivência e formação de calos, em comparação com as demais cultivares em estudo, sendo que a cultivar Fuyu apresentou resultados inferiores (Tabela 2). Para o número de raízes por estaca, a cultivar Pomelo apresentou melhores resultados. Esses resultados concordam com Nishimoto (1994) que, trabalhando com o enraizamento de estacas herbáceas de caquizeiro cultivares Pomelo, Taubaté e Rama Forte, verificou que o Pomelo apresentou maior número de raízes por estacas, apesar de também ter ocorrido poucas raízes nas estacas.

Embora não tenha ocorrido diferença significativa para a porcentagem de enraizamento, verifica-se, pela Tabela 2, que houve emissão de raízes em todas as cultivares em estudo, apesar de a formação radicular ser mínima e aleatória, o que ocasionou elevado coeficiente de variação. Nishimoto (1994) também verificou baixa capacidade de enraizamento, constatando em seu estudo 18,96\% para a cultivar Pomelo, $15,68 \%$ para o cultivar Rama Forte e apenas $0,86 \%$ para a cultivar Taubaté.

A formação de raízes adventícias em estacas pode ser direta e indiretamente controlada por genes, sendo que os aspectos genéticos que influenciam no processo de enraizamento de estacas não têm sido

TABELA 2 - Porcentagens de estacas enraizadas (PEE), sobrevivência (PS), formação de calos (PFC), brotação (PB) e número de raízes por estaca (NRE) de estacas herbáceas de cultivares de caquizeiro. ESALQ/USP, Piracicaba-SP, 2004.

\begin{tabular}{|c|c|c|c|c|c|}
\hline Cultivares & PEE $(\%)^{1 *}$ & PS $(\%)^{2} * *$ & PC $(\%)^{3 * *}$ & PB $(\%)^{4 *}$ & $\mathrm{NRE}^{5 * *}$ \\
\hline Pomelo & 13,17 & $39,30 \mathrm{~b}$ & $37,00 \quad b$ & 4,05 & $2,22 \quad a$ \\
\hline Rama Forte & 7,32 & $49,96 \mathrm{~b}$ & $49,96 \mathrm{~b}$ & 11,17 & $0,11 \quad b$ \\
\hline Taubaté & 5,70 & 73,89 a & 68,72 a & 4,05 & $0,11 \quad b$ \\
\hline Giombo & 5,70 & $43,42 \quad b$ & $35,97 \quad b$ & 8,63 & $0,09 \quad b$ \\
\hline Fuyu & 4,05 & $6,59 \quad \mathrm{c}$ & $5,70 \quad c$ & 4,05 & $0,09 \quad b$ \\
\hline CV (\%) & 76,13 & 19,34 & 24,89 & 116,61 & 207,43 \\
\hline
\end{tabular}

* Médias não diferem pelo teste $\mathrm{F}$ da análise de variância ${ }^{(1 \mathrm{e})}$. ** Médias diferem estatisticamente entre si, na coluna, ao nível de $5 \%$ de probabilidade, pelo teste Scott-Knott ${ }^{(2,3 \text { e } 5)}$. 
investigados (Haissig \& Reimenschneider, 1988). A potencialidade de uma estaca em formar raízes é variável com a espécie e cultivar, podendo ser feita uma classificação entre espécies ou cultivares de fácil, médio ou difícil capacidade de enraizamento, ainda que a facilidade de enraizamento seja resultante da interação de diversos fatores e não apenas do potencial genético (Fachinello et al., 1995).

Biasi et al. (2002) verificaram que a utilização de AIB não apresentou efeito positivo na emissão de raízes em estacas semilenhosas de caquizeiro 'Fuyu'. Estacas herbáceas de caquizeiro 'Giombo', tratadas com diferentes concentrações de AIB via imersão rápida, não sobreviveram até os 120 dias após o estaqueamento (Rubbo, 1989). As auxinas são reguladores de crescimento que induzem a formação de raízes em estacas e, freqüentemente, são consideradas como limitantes do enraizamento, podendo apresentar pouco ou nenhum efeito em espécies de difícil enraizamento (Wilson, 1994).

Assim, concluiu-se que as cultivares de caquizeiro apresentam diferenças quanto ao potencial de formação de raízes e brotações; estacas herbáceas apresentam maior tendência na propagação via estaquia em comparação com as estacas lenhosas.

\section{REFERÊNCIAS}

ALVARENGA, A.A. Substâncias de crescimento e regulação do desenvolvimento vegetal. Lavras: UFLA, 1990.59p.

BIASI, L.A. Emprego do estiolamento na propagação de plantas. Ciência Rural, Santa Maria, v. 26, n. 2, p. 309-315, 1996.

BIASI, L.A.; CARVALHO, D.C.; WOLF, G.D.; ZANETTE, F. Potencial organogenético de tecidos caulinares e radiculares de caquizeiro. Revista Brasileira de Fruticultura, Jaboticabal, v. 24, n. 1, p. 29-34, 2002.

FACHINELLO, J.C.; HOFFMANN, A.; NACHTIGAL, J.C.; KERSTEN, E.; FORTES, G.R. de L. Propagação de plantas frutíferas de clima temperado. 2. ed. Pelotas: UFPel, 1995. 178p.

FERREIRA, D.F. Análise estatística por meio do SISVAR (Sistema para Análise de Variância) para Windows versão 4.0. In: REUNIÃO ANUAL DA REGIÃO BRASILEIRA DA SOCIEDADE INTERNACIONALDE BIOMETRIA, 45., 2000, São Carlos. Anais... São Carlos: UFSCar, 2000. p. 255-258.

FIGUEIREDO, S.L.B.; KERSTEN, E.; SCHUCH, M.W. Efeito do estiolamento parcial e do ácido indolbutírico (AIB) no enraizamento de estacas de goiabeira serrana (Feijoa sellowiana Berg). Scientia Agrícola, Piracicaba, v. 52, n. 1, p. 167-171, 1995.

GOMES, F. P. Curso de estatística experimental. 14.ed. Piracicaba: USP/ ESALQ, 2000.477p.

HAISSIG, B.E.; REIMENSCHNEIDER, E.D. Genetic effects on adventitious rooting. In: DAVIS, T. D.; HAISSIG, B. E.; SANKLHA, N. (Ed.). Adventitious root formation in cuttings. Portland: Discorides Press, 1988. p. 47-60.

HARTMANN, H.T.; KESTER, D.E.; DAVIES JUNIOR, F.T.; GENEVE, R.L. Plant propagation: principles and practices. $7^{\text {th }}$ ed. New Jersey: Prentice Hall, 2002. 880p.

HINOJOSA, G.F. Auxinas. In: CID, L. P B. Introdução aos hormônios vegetais. Brasília: EMBRAPA, 2000. p. 15-54.

NISHIMOTO, C.H. Efeito do ácido indolbutírico no enraizamento de estacas herbáceas de caqui (Diospyrus kaki L.). 1994. 51f. Monografia (Trabalho de Graduação em Agronomia) - Universidade Estadual Paulista, Faculdade de Ciências Agrárias e Veterinárias, Jaboticabal, 1994.

PASQUAL, M.; CHALFUN, N.N.J.; RAMOS, J.D.; VALE, M.R. do; SILVA, C.R. de R. e. Fruticultura Comercial: propagação de plantas frutíferas. Lavras: UFLA/FAEPE, 2001. 137p.

PIO, R.; SCARPARE FILHO, J.A.; MOURÃO FILHO, F.A.A. A cultura do caquizeiro. Piracicaba: ESALQ/USP, 2003. 35p. (Série Produtor Rural, 23).

RUBBO, M.S. Estudo do enraizamento de estacas de caquizeiro (Diospyros kaki L.). 1989. 90f. Dissertação (Mestrado em Fitotecnia) - Escola Superior de Agricultura “Luiz de Queiroz", Universidade de São Paulo, Piracicaba, 1989.

SCOTT, A.J.; KNOTT, M. A cluster analysis method for grouping means in the analysis of variance. Biometrics, Washington, v. 30, p. 507$512,1974$.

TAO, R.; SUGIURA, A. Micropropagation of japanese persimmon (Diospyros kaki L.). In: BAJAJ, Y.P.S. Biotechnology in agriculture and forestry: high-tech and micropropagation II. Berlin: SpringerVerlag, 1992. v. 18, p. 423-440.

WILSON, P. J. The concept of a limiting rooting morphogen in woody stem cuttings. Journal of Horticultural Science, Calcutta, v. 69, n. 4,p. 591-600, 1994. 